
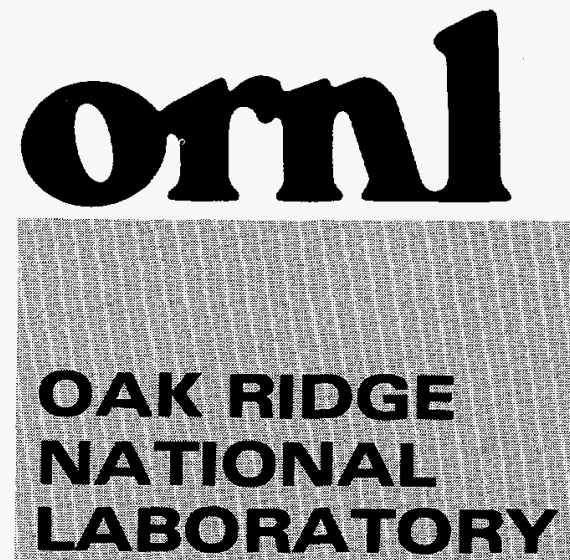

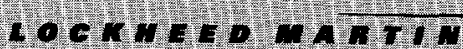

\author{
CRADA Final Report \\ for \\ CRADA Number ORNL 94-0274 \\ GROWTH OF LARGE DETECTOR
CRYSTALS \\ L. A. Boatner \\ Oak Ridge National Laboratory
}

Stuart Samuelson

Deltronic Crystal Industries

Dover, New Jersey RECEIVED

Au6 21999

OSTI

\title{
Solid State Division
}

Oak Ridge National Laboratory

P.O. Box 2008

Oak Ridge, Tennessee 37831-6056

managed by

LOCKHEED MARTIN ENERGY

RESEARCH CORP. for the

U.S. DEPARTMENT OF ENERGY

under contract DE-AC05-96OR22464

Approved for Public release;

distribution is unlimited.

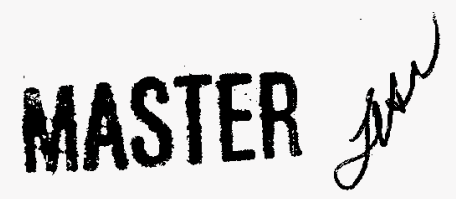

WMNAGEO AND OPERATED BY

LOCKHEEO MARTN ENERGY RESEARCH CORPORATIOH

DISTRIBUTION OF THIS 
This report has been reproduced directly from the best available copy.

Available to DOE and DOE contractors from the Office of Scientific and Technical Infotmation, P. O. Box 62, Oak Ridge, TN 37831; prices available from (423) 576-8401, FTS 626-8401.

Available to the public from the National Technical Information Service, U.S. Department of Commerce, 5285 Port Royal Road, Springfield, VA 22161.

This report was prepared as an account of work sponsored by an agency of the United States Government. Neither the United States Government nor any agency thereof, nor any of their employees, makes any warranty, express or implied, or assumes any legal liability or responsibility for the accuracy, completeness, or usefulness of any information, apparatus, product, or process disclosed, or represents that its use would not infringe privately owned rights. Reference herein to any specific commercial product, process, or service by trade name, trademark, manufacturer, or otherwise, does not necessarily constitute or imply its endorsement, recommendation, or favoring by the United States Government or any agency thereof. The views and opinions of authors expressed herein do not necessarily state or reflect those of the United States Government of any agency thereof. 


\section{DISCLAIMER}

Portions of this document may be illegible electronic image products. Images are produced from the best available original document. 
CRADA Final Report

for

CRADA Number ORNL 94-0274

\title{
GROWTH OF LARGE DETECTOR CRYSTALS
}

\author{
L. A. Boatner \\ Oak Ridge National Laboratory \\ Stuart Samuelson \\ Deltronic Crystal Industries \\ Dover, New Jersey \\ Prepared by the \\ OAK RIDGE NATIONAL LABORATORY \\ managed by \\ LOCKHEED MARTIN ENERGY RESEARCH CORP. \\ for the U.S. Department Of Energy \\ under contract DE-AC05-96OR22464
}

This work was supported through a CRADA with Deltronic Crystal Industries, Dover, New Jersey sponsored by the Laboratory Technology Research Program, Office of Energy Research, U.S. Department of Energy, under contract DE-AC05-96OR22464 with Oak Ridge National Laboratory, managed by Lockheed Martin Energy Research Corporation. 


\author{
Final Report Certification \\ for \\ CRADA Number 94-0274 \\ between \\ Lockheed Martin Energy Research, Inc. \\ and \\ - Deltronic Crystal Industries \\ (Participant)
}

The following certification is made for the subject final report:

1a) The final report contains a claim that information contained in the final report is qualifying as "Protected CRADA Information" (PCI) and any PCI is identified as such in the report;

or

XX 1b) neither Energy Research nor the participant asserts any claim to information contained in the final report as qualifying as "Protected CRADA Information";

2) that Energy Research and the participant has no objection to public distribution of the final report due to patentable information, and

3) the final report contains no proprietary information

For the Participant:

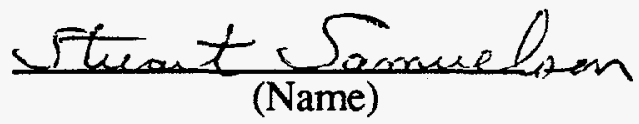

Stuart Samuelson, President

Deltronic Crystal Industries

(Title)

June 16,1997

(Date)

Instructions:

The above certification can be made using this form or may be put on company letterhead if the participant desires.

Mark the appropriate statament in 1a or $1 \mathrm{~b}$ above with an " $\mathrm{X}$ ". Refer to the articles in the CRADA terms and conditions governing the identification and marking of Protected CRADA Information.

If no $\mathrm{PCI}$ is identified, the report will be distibuted without restriction. If $\mathrm{PCI}$ is identified, the report distribution will be limited in accordance with the CRADA terms and conditions governing release of data. In all cases items 2 and 3 must be true. That is, the report can not contain proprietary information and a discloseure must be filed prior to release of the report. 


\title{
GROWTH OF LARGE DETECTOR CRYSTALS
}

\section{CRADA ORNL94-0274}

\author{
Final Report
}

\author{
PI: L. A. Boatner, Oak Ridge National Laboratory, Solid State Division \\ PARTICIPANT : Deltronic Crystal Industries, Dover, New Jersey
}

\begin{abstract}
In the course of a collaborative research effort between L. A. Boatner of Oak Ridge National Laboratory and Prof. Alex Lempicki of the Department of Chemistry of Boston University, a new highly efficient and very fast scintillator for the detection of gammarays was discovered. This new scintillator consists of a single crystal of lutetium orthophosphate $\left(\mathrm{LuPO}_{4}\right)$ to which a small percentage of trivalent cerium is added as an activator ion. The new lutetium orthophosphate-cerium scintillator was found to be superior in performance to bismuth germanium oxide - a material that is currently widely used as a gamma-ray detector in a variety of medical, scientific, and technical applications. The medical applications of gamma-ray scintillators of this type include their use in positron-emission-tomography systems for medical diagnostics and imaging; and similar detectors have applications in the fields of high energy physics, environmental monitoring, nuclear physics, and materials science. Single crystals of $\mathrm{LuPO}_{4}$ and related rare-earth orthophosphates had been grown for a number of years in the ORNL Solid State Division prior to the discovery of the efficient gamma-rayscintillation response of $\mathrm{LuPO}_{4}: \mathrm{Ce}$. The high-temperature-solvent (flux-growth) method used for the growth of these crystals was capable of producing crystals in sizes that were adequate for research purposes but that were inadequate for commercial-scale production and widespread application.

The CRADA between ORNL and Deltronic Crystal Industries of Dover, NJ was undertaken for the purpose of investigating alternate approaches, such as top-seededsolution growth, to the growth of $\mathrm{LuPO}_{4}$ :Ce scintillator crystals in sizes significantly larger than those obtainable through the application of standard flux-growth methods and, therefore, suitable for commercial sales and applications.
\end{abstract}




\section{CRADA OBJECTIVES}

\section{Commercial Objectives}

As a result of the increasing application of gamma-ray scintillators in the fields of medical diagnostics, environmental monitoring, and non-destructive testing, the market for new scintillator materials continues to grow. A new, highly efficient and fast-responding scintillator for the detection of gamma-rays was discovered in a collaborative effort between L. A. Boatner at Oak Ridge National Laboratory (ORNL) and Prof. Alex Lempicki of the Department of Chemistry at Boston University. The new scintillator $\left(\mathrm{LuPO}_{4}: \mathrm{Ce}^{3+}\right.$ ) was determined to have a light output for gamma-ray detection that is twice that of bismuth germanium oxide or BGO (a widely used scintillator material) and to be an order of magnitude faster than BGO.

The discovery of the new orthophosphate scintillator was made using single crystals which were grown by means of a high-temperature-solvent or "flux" technique. This method generally produces numerous relatively small single crystals as a result of uncontrolled spontaneous nucleation. It is not capable of producing scintillator single crystals of a size that is sufficient for commercialization. Accordingly, the long-term commercial objective of the ORNL/Deltronic Crystal Industries (DCI) small CRADA was to develop a new gamma-ray scintillator product based on $\mathrm{LuPO}_{4}: \mathrm{Ce}^{3+}$ that would become commercially viable through the development of improved crystal-growth techniques.

It was understood that the realization of this long-term commercial objective could not be achieved by means of the subject CRADA whose duration and funding level were limited. The subject CRADA was, therefore, viewed as an initial step in the realization of a longer-term goal, and it was anticipated that the results obtained in the course of the initial relatively limited effort would form the basis for a followon proposal directed toward obtaining support for a normal CRADA of three-years duration. Unfortunately, the period corresponding to the ending date of the subject ORNL/DCI small CRADA corresponded to the time during which severe funding cuts were made in the overall CRADA program, and follow-on funding to support a longer-term effort was not available. Nevertheless, the performance characteristics of gamma-ray detectors based on $\mathrm{LuPO}_{4}: \mathrm{Ce}^{3+}$ are such that this material is still a competitive option in the commercial area of radiation detection and medical diagnostics. 


\section{Technical Objectives}

A procedure for the preparation of single crystals of the rare-earth orthophosphates by a slow-cooling method from a flux (or high-temperature solvent) was first reported by Feigelson [1]. Subsequently, the entire series of lanthanide orthophosphates of the form $\mathrm{LnPO}_{4}$ have been prepared by means of this technique. As noted above, although this technique is perfectly adequate for the preparation of samples that are sufficiently large for most research investigations, the technique has limited capability if large crystals with reproducible relatively large sizes and high quality are required for device applications. While the doped crystal system $\mathrm{LuPO}_{4}: \mathrm{Ce}^{3+}$ (LOP) has been shown to possess remarkable scintillation properties under gamma-ray excitation, obtaining single crystals of this material in a large and consistent size represents a major obstacle to its commercialization. The alternate approach to improving on the relatively uncontrolled nucleation processes inherent in the flux-growth method explored by Feigelson [1] is the technique of top-seeded solution growth (TSSG) - a method that has been applied successfully to a number of other important single-crystal systems.

The flux or high-temperature solvent that is used in the flux method developed by Feigelson [1] is lead pyrophosphate or $\mathrm{Pb}_{2} \mathrm{P}_{2} \mathrm{O}_{7}$, which has been shown to have an appreciable solubility for LOP. While solubility is an important factor in the application of the TSSG method, the lead pyrophosphate flux is characterized by some other negative factors. These factors include the fact that the flux contains lead and, therefore, represents a safety factor from the point of view of human toxicity and also presents an associated economic and practical problem of the disposal of a material that is classified as a hazardous waste. One of the major technical goals of the subject CRADA, in addition to investigating the general applicability of TSSG methods to the growth of large LOP single crystals, was to identify an alternate flux that did not contain lead and, thereby, to develop a crystal-growth approach that could be easily and economically implemented in the context of a commercial production operation.

Based on information published in the open scientific literature[2], it appeared that an alternate flux for the growth of LOP had been identified in prior work. This alternate flux material was reported to be $\mathrm{K}_{4} \mathrm{P}_{2} \mathrm{O}_{7}$ - a compound that did not contain lead. The $\mathrm{K}_{4} \mathrm{P}_{2} \mathrm{O}_{7}$ flux (unlike $\mathrm{Pb}_{2} \mathrm{P}_{2} \mathrm{O}_{7}$ which must be removed from the rare-earth orthophosphate single crystals by boiling in concentrated nitric acid) is soluble in water, thereby permitting the relatively easy removal of residual flux from the as- 
grown single crystals. Accordingly, a major technical goal of the subject CRADA was to investigate the applicability of the $\mathrm{K}_{4} \mathrm{P}_{2} \mathrm{O}_{7}$ flux and of related alkali-based fluxes, such as $\mathrm{Na}_{4} \mathrm{P}_{2} \mathrm{O}_{7}$, to the TSSG growth of large single crystals of LOP in order to develop a commercially feasible process.

\section{CRADA Objectives - Results}

Experiments designed to identify and characterize new, lead-free fluxes for the growth of large single crystals of $\mathrm{LuPO}_{4}$ :Ce scintillator crystals by means of the TSSG technique were carried out jointly by DCI and ORNL. The experiments in which sodium-based orthophosphate fluxes were utilized proved to be unsuccessful, and no crystal growth of any type was observed using a wide range of growth conditions (e.g. cooling rates, maximum growth temperatures, soak times, etc.) The flux-based crystal-growth experiments in which a potassium pyrophosphate flux $\left(\mathrm{K}_{4} \mathrm{P}_{2} \mathrm{O}_{7}\right)$ was utilized, however, yielded large, optical-quality single crystals.

While the crystals grown using the $\mathrm{K}_{4} \mathrm{P}_{2} \mathrm{O}_{7}$ flux displayed a growth habit that differed somewhat from the growth habit characteristic of $\mathrm{LuPO}_{4}$ crystals grown using the traditional lead pyrophosphate flux, their other physical characteristics closely resembled those of lutetium orthophosphate. An examination of the structural properties of these crystals, however, revealed that the compound that had crystallized was not $\mathrm{LuPO}_{4}$, but was, in fact, a new crystalline phase that contained the three cations: potassium, lutetium, and phosphorous. This new compound when doped with cerium proved to be an efficient scintillator in its own right, and characterization data detailing the light output and response times were obtained. These data indicated that the performance characteristics of the $\mathrm{LuPO}_{4}: \mathrm{Ce}$ system were still superior to the new cerium-doped compound.

The joint DCI and ORNL crystal-growth experiments on the application of alkali pyrophosphate fluxes to the growth of $\mathrm{LuPO}_{4}$ :Ce were successful in proving that results published by others in the open scientific literature were in error and that by using these fluxes, in actuality, a new compound was formed that was also an efficient scintillator. Ultimately, however, this line of investigation did not measurably advance the CRADA effort toward the original goal of developing a new and reproducible method for the growth of large, commercially viable single crystals of $\mathrm{LuPO}_{4}: \mathrm{Ce}^{3+}$. Accordingly, at this juncture, a significant portion of the CRADA funds and the CRADA period of performance had been expended. Therefore, the remaining funding resources and time were then directed toward new experiments 
that emphasized and focused on the determination of the appropriate growth parameters for use in the TSSG growth of $\mathrm{LuPO}_{4}$ :Ce crystals using the lead pyrophosphate flux that had been traditionally employed in standard flux-growth runs. These experiments encompassed determinations of the solubility of the lutetium orthophosphate compound in the molten $\mathrm{Pb}_{2} \mathrm{P}_{2} \mathrm{O}_{7}$ flux as a function of temperature. Some initial top-seeded-solution-growth runs were then made with limited success and, at this point, the CRADA resources of both the participant and the contractor had been expended, a no-cost extension of the period of performance had expired, and funding cuts in the overall CRADA program obviated a continuation of the cooperative research and development program between ORNL and $\mathrm{DCI}$ in the form of a long-term large CRADA. It should be noted that during this period, DCI was also able to obtained a Phase I SBIR grant to carry out research on the growth of single crystals of the orthophosphates - including $\mathrm{LuPO}_{4}: \mathrm{Ce}$ single crystals for scintillator applications.

\section{CRADA-Derived Benefits to DOE}

The experimental findings resulting from this CRADA have been valuable to the advancement of an ongoing ORNL Program that is currently funded by the DOE Office of Nuclear Nonproliferation (NN-20). Under this program, the development of cerium-doped orthophosphate-based scintillators for gamma-ray detection has continued to the point where a fieldable, highly portable gamma-ray detection instrument based on the use of $\mathrm{LuPO}_{4}$ :Ce scintillator crystals has been designed and is currently in the final stages of assembly and testing. Specifically, the application of the alkali-based pyrophosphate flux compositions to the growth of single crystals of $\mathrm{LuPO}_{4}: \mathrm{Ce}^{3+}$ had been planned as a part of this effort, and the CRADA project provided an opportunity to explore this avenue of orthophosphate crystal growth in an independent mode that also afforded the opportunity for direct commercialization of the alternate process had it been successful. In the course of the CRADA, a new cerium-activated scintillator material was discovered which may prove to have properties that will find special applications in the physical sciences or in radiation monitoring. The performance of this new scintillator is relatively close to that of the $\mathrm{LuPO}_{4}: \mathrm{Ce}^{3+}$ system, and it is possible that, in the future, its performance may be enhanced by either changes in the cerium doping levels or by the addition of other rare-earth activator ions. If this proves to be the case, an additional competitive scintillator material for gamma-ray detection will be available. 
The rare-earth orthophosphates, of which $\mathrm{LuPO}_{4}$ is the end member compound, have been investigated in research projects supported by the Division of Materials Sciences of The Office of Basic Energy Sciences (BES) of the U.S.D.O.E. for a number of years. Initially, the lanthanide orthophosphates were studied for potential applications as extremely stable polycrystalline host materials for the incorporation and long-term storage of high-level nuclear wastes. More recently (beginning in FY 1997), a new program of research dealing with the rare-earth orthophosphates has been funded as part of the Program for Environmental Management (EMSP) activities of D.O.E. One of the purposes of this effort is to investigate the potential use of polycrystalline ceramics of these materials as a medium for the storage of plutonium resulting from the dismantling of nuclear weapons. The experience gained from the crystal-growth activities associated with the ORNL/DCI CRADA will be useful in this new D.O.E.-funded effort. In particular, the results obtained in the CRADA-supported investigations of interactions between the lanthanide orthophosphates and the alkali pyrophosphates will be of value in the study and identification of sintering aids for the preparation and densification of nuclear-wastebearing orthophosphate ceramics at low sintering temperatures.

The rare-earth orthophosphates, including $\mathrm{LuPO}_{4}$ in both pure and doped forms, are presently being extensively investigated using neutron scattering and neutron diffraction techniques in a collaborative BES-supported program between the Argonne National Laboratory and ORNL. This joint effort utilizes the Intense Pulsed Neutron Source at Argonne and has yielded new and interesting results concerning the phonon and magnetic properties of the lanthanide orthophosphates. The new lutetium-containing compound discovered in carrying out the ORNL/DCI CRADA will be investigated in future D.O.E.-supported investigations that will be accomplished using the spallation neutron source at the IPNS. Accordingly, the results obtained in the course of the ORNL/DCI CRADA have benefited and will continue to benefit research and development programs supported by several D.O.E. offices.

\section{Technical Results}

A series of crystal-growth experiments was carried out for the purpose of developing new high-temperature solvents or "fluxes" which would represent an alternative to the lead pyrophosphate fluxes that had been traditionally employed in the growth of single crystals of $\mathrm{LuPO}_{4}$ and the other rare-earth orthophosphates. 
These experiments were based on a previous publication[2] by other workers in the open literature in which the successful growth of orthophosphate single crystals was reported through the use of the alkali pyrophosphate $\mathrm{K}_{4} \mathrm{P}_{2} \mathrm{O}_{7}$. In this work, the use of $\mathrm{K}_{4} \mathrm{P}_{2} \mathrm{O}_{7}$ was reported to yield relatively large and high-optical-quality single crystals of $\mathrm{LuPO}_{4}$. This alternative flux to $\mathrm{Pb}_{2} \mathrm{P}_{2} \mathrm{O}_{7}$ appeared to offer the advantages of: a highly desirable lower growth temperature, the ability to remove the flux from the rare-earth orthophosphate single crystals by using a water solvent as opposed to the boiling nitric acid leaching required for the removal of lead pyrophosphate flux, and most importantly, the elimination of the use of lead - a substance with an established human toxicity and a material that involves the expense and difficulty of the disposal of commercially generated hazardous waste. Finally, the crystal-growth habit reported in the earlier open literature publication differed from the long "barlike" crystal habit generally obtained through the use of a $\mathrm{Pb}_{2} \mathrm{P}_{2} \mathrm{O}_{7}$ flux. This suggested that the alkali pyrophosphate flux might provide an advantage in yielding a desirable change of growth habit that could then be exploited in the ultimate application of top-seeded-solution growth to the $\mathrm{LuPO}_{4}: \mathrm{Ce}^{3+}$ system.

Following the development of techniques for the synthesis of the alkali pyrophosphate fluxes for use in the growth of $\mathrm{LuPO}_{4}: \mathrm{Ce}^{3+}$, crystal-growth runs were carried out using both $\mathrm{K}_{4} \mathrm{P}_{2} \mathrm{O}_{7}$ and $\mathrm{Na}_{4} \mathrm{P}_{2} \mathrm{O}_{7}$ fluxes. These initial crystal-growth experiments involved the study of the effects of the maximum growth temperature and of cooling rates on the formation of crystalline phases. No crystallization of any phase was observed in the case of the use of the sodium pyrophosphate flux regardless of the maximum growth temperature or cooling rate employed, and this flux was not investigated further.

The application of a potassium pyrophosphate flux to the high-temperature solvent process was found to yield relatively large and well-formed, optical-quality pyrophosphate single crystals, as reported previously in the literature [2]. Accordingly characterization studies of these single crystals were undertaken. An analysis of the structural properties of the crystals grown using a $\mathrm{K}_{4} \mathrm{P}_{2} \mathrm{O}_{7}$ flux was carried out by means of $x$-ray powder diffraction, and this analysis revealed that the crystals did not have the tetragonal xenotime (or zircon) structure characteristic of $\mathrm{LuPO}_{4}$ and that, accordingly, another compound had been formed. Further examination of the crystals using energy-dispersive $X$-ray analysis indicated that the compound that had crystallized contained all three of the metal cations present in the crystal-growth charge: potassium, lutetium, and phosphorous. A subsequent search of the existing crystallographic data bases using the compositional and structural 
information obtained from the x-ray analysis failed to identify a known compound whose properties corresponded to those of the phase crystallized in the growth experiments utilizing the potassium pyrophosphate flux. A full crystallographic single crystal structural analysis has subsequently been undertaken but, thus far, the refinement of the structure of this new compound has proven to be very difficult, and a full refinement is presently not available.

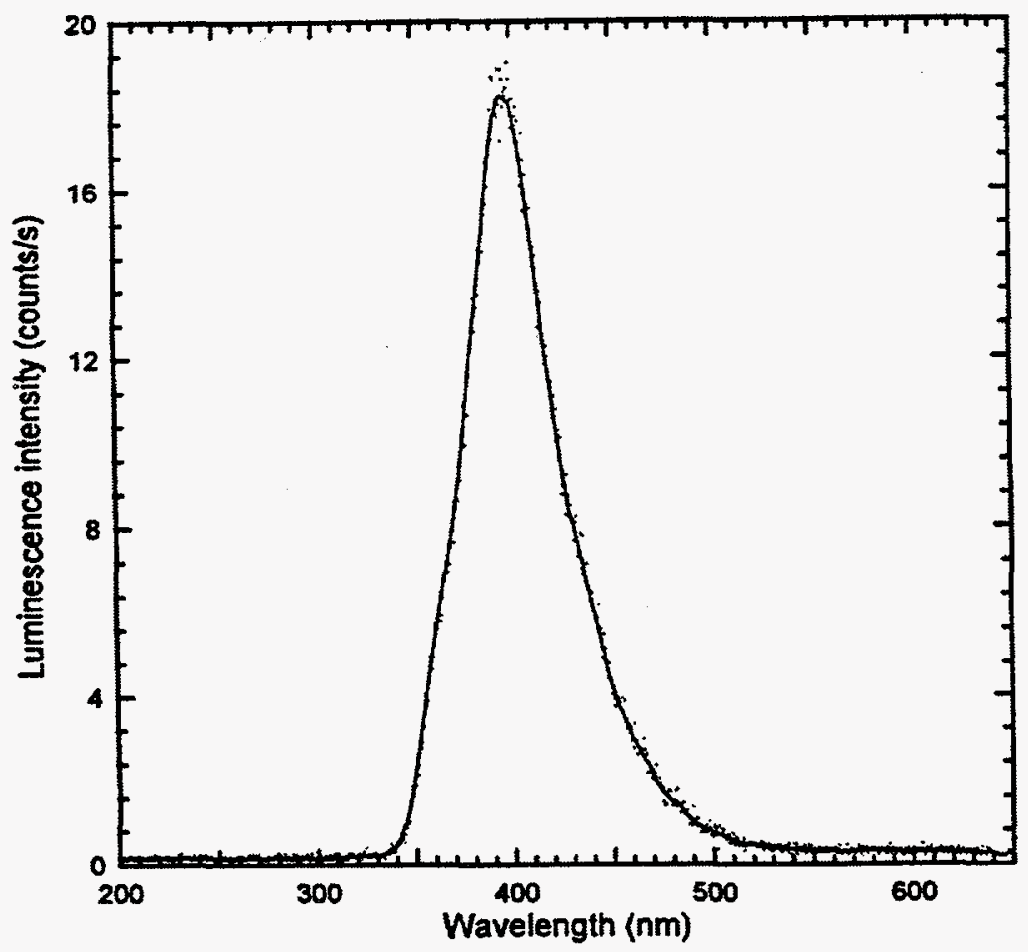

Figure 1. The luminescence spectrum of a cerium-activated single crystal of postassium lutetium phosphate grown by a flux technique from $2 \mathrm{~K}_{4} \mathrm{P}_{2} \mathrm{O}_{7}$ flux. The spectrum was produced by gammaray excitation at room temperature.

Concurrently with the structural and physical characterization of the phase crystallized using the $\mathrm{K}_{4} \mathrm{P}_{2} \mathrm{O}_{7}$ flux, the luminescence properties of the cerium-doped single crystals of the new compound were determined as part of an ongoing collaboration with Prof. Alex Lempicki of the Chemistry Department of Boston University. The luminescence spectra stimulated by gamma-ray excitation of the $\mathrm{K}_{\mathrm{x}} \mathrm{L}_{\mathrm{y}} \mathrm{P}_{\mathrm{n}} \mathrm{O}_{\mathrm{z}}$ composition crystallized from the $\mathrm{K}_{4} \mathrm{P}_{2} \mathrm{O}_{7}$ flux is shown in Fig. 1 . This particular sample was grown at Deltronic Crystal Industries, and identical excitation spectra were obtained using crystals grown at ORNL with the $\mathrm{K}_{4} \mathrm{P}_{2} \mathrm{O}_{7}$ flux. The gamma-ray excitation produces an intense luminescence beginning around $340 \mathrm{~nm}$ 
and extending out to about $500 \mathrm{~nm}$. The luminescence signal peaks at approximately $400 \mathrm{~nm}$. No other gamma-ray-excited luminescence signals were observed for this compound.

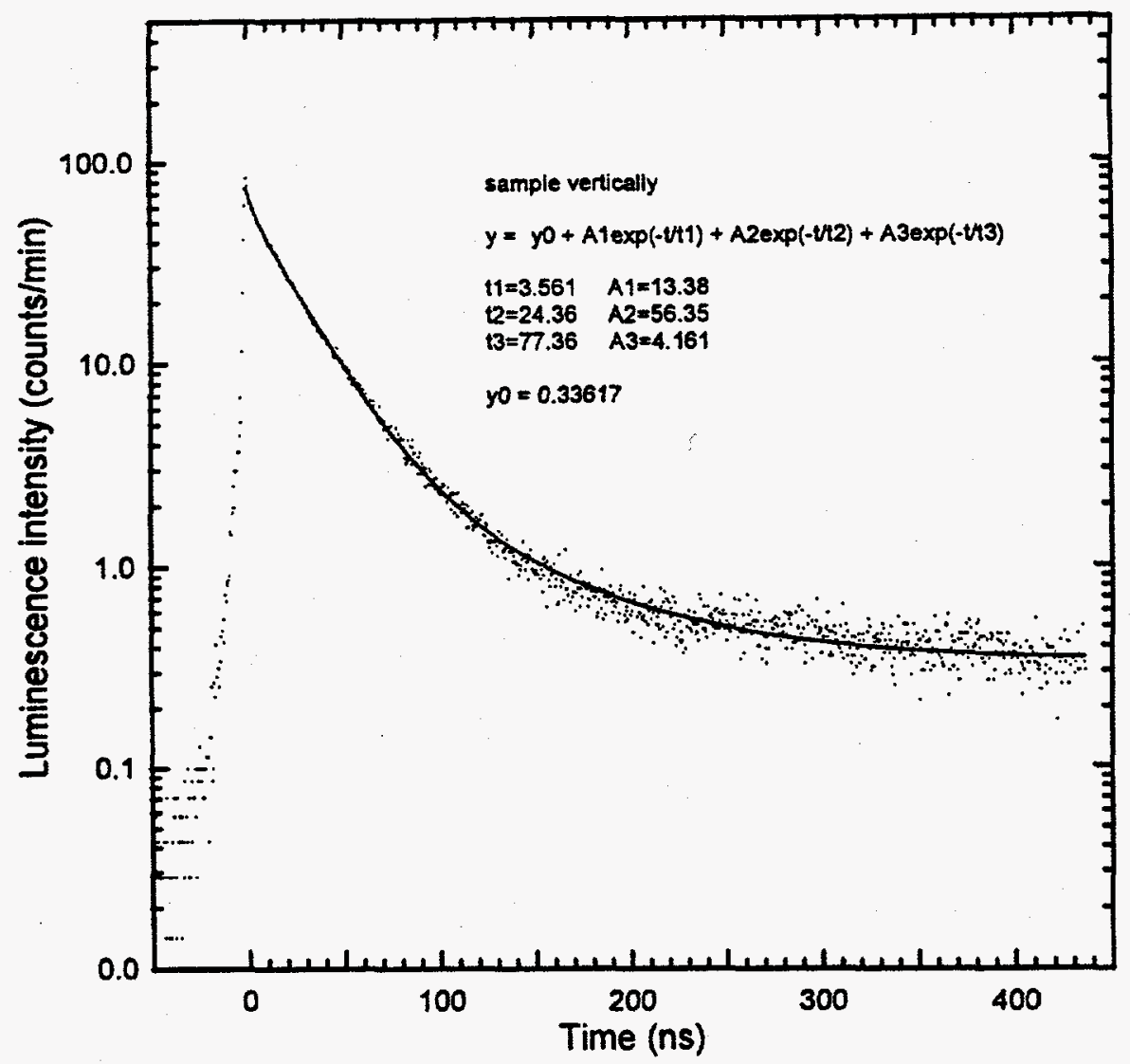

Figure 2. Luminescence decay under gamma-ray excitation for a cerium activated single crystal of a potassium lutetium phosphate grown by a flux technique from a $\mathrm{K}_{4} \mathrm{P}_{2} \mathrm{O}_{7}$ flux. The luminescence spectrum includes all of the wavelengths of the band shown in Figure 1.

Measurements of the luminescence-decay response times of the ceriumactivated potassium lutetium phosphate composition crystallized from a $\mathrm{K}_{4} \mathrm{P}_{2} \mathrm{O}_{7}$ flux were made with the sample at room temperature. The results, which represent the luminescence decay under gamma-ray excitation for all wavelengths in the emission band, are shown in Figure 2. The decay curve consists of multiple components, and the nominal decay time is approximately $50 \mathrm{~ns}$ (i.e. the decay time is about twice that of the $\mathrm{LuPO}_{4}$ :Ce scintillator.) These results still make this a very fast scintillator material that may ultimately find use for special applications - particularly if the TSSG growth of this compound proves to be more straightforward than that of the $\mathrm{LuPO}_{4}: \mathrm{Ce}^{3+}$ system. 


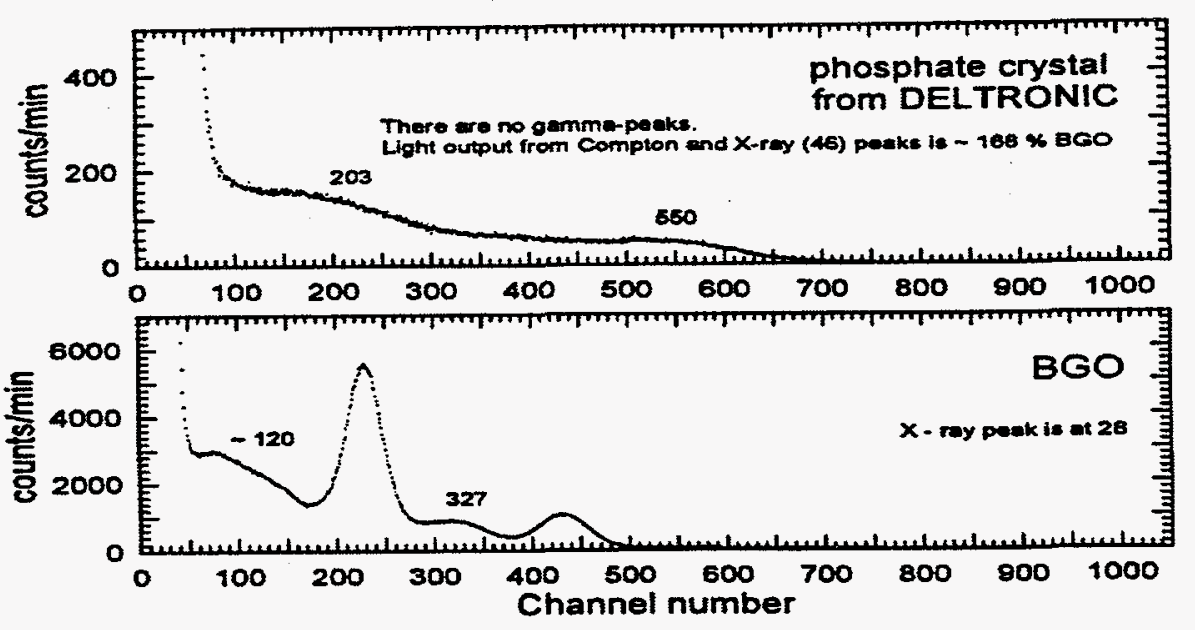

Figure 3. The energy spectrum obtained for a single crystal of a cerium-activated potassium lutetium phosphate grown using a $\mathrm{K}_{4} \mathrm{P}_{2} \mathrm{O}_{7}$ flux. The energy spectrum of a bismuth germanium oxide scintillator is shown for comparison purposes.

The energy spectrum of the cerium-doped potassium lutetium phosphate composition was determined, and these results are illustrated in Figure 3 and compared with the results characteristic of bismuth germanium oxide (BGO), a presently widely used commercial scintillator material. The integrated light output from the Compton and $x$-ray peaks for the phosphate scintillator was found to be $168 \%$ of that characteristic of BGO making this material both an efficient and fast scintillator.

Pending the successful completion of the single-crystal structural refinement effort and the associated determination of the precise structural properties of the potassium lutetium phosphate compound formed through the use of a $\mathrm{K}_{4} \mathrm{P}_{2} \mathrm{O}_{7}$ flux, a journal publication will be prepared detailing the physical and luminescence properties of this new material.

\section{Inventions}

At this point in time, no reports of invention have been prepared as a result of the ORNL/DCI CRADA. However, pending the successful completion of the singlecrystal structural refinement work discussed in the previous section and possible results of experiments designed to explore the optimization of the cerium-doped potassium lutetium phosphate compound, such action may be taken in the future. 


\section{Assessment of Commercialization Possibilities}

The potential for the commercialization of the $\mathrm{LuPO}_{4}$ :Ce gamma-ray scintillator is still an attractive possibility if the crystal-growth problems associated with the large-scale commercial growth of this material can be resolved in the future. The fact that these problems proved to be intractable under the limitation imposed by both the funding level and time constraints of a small CRADA activity does not diminish the luminescence properties that make the $\mathrm{LuPO}_{4}$ system a highly efficient and fast gamma-ray detector. In fact, the crystal sizes that can presently be obtained by straightforward flux-growth methods are satisfactory for some applications as noted previously.

\section{Plans for Future Collaborations}

In the absence of additional funding at the level of a multi-year CRADA, further collaboration between ORNL and DCI on the growth of single crystals of $\mathrm{LuPO}_{4}: \mathrm{Ce}^{3+}$ appears to be unlikely. The magnitude of the technical problems associated with adapting the top-seeded-solution-growth technique to the commercial-scale production of large lutetium orthophosphates single-crystals was, as initially anticipated, beyond the scope of a small CRADA activity. It should be noted, however, that $\mathrm{LuPO}_{4}$ and related rare-earth orthophosphate single-crystal materials are presently the subject of collaborative work between ORNL and the Lawrence Berkeley Laboratory (high resolution spectroscopy of rare-earths and actinides incorporated in rare-earth orthophosphate hosts, Argonne National Laboratory (neutron diffraction and scattering studies of lanthanide orthophosphates, The University of New Mexico (investigations of heavy-particle radiation-damage effects in the rare-earth orthophosphates), The University of Central Florida, Center for Research on Electro-Optics and Lasers (the application of rare-earth orthophosphates as laser hosts for microlaser development), and the Rockwell Science Center (the application of rare-earth orthophosphates as weak interfaces in ceramics and as advanced ceramics for the disposal of high-level radioactive wastes.). 


\section{Conclusions}

While the overall technical goals of the small CRADA project could not be met within the funding and time constraints and funding cuts in the CRADA program on a national scale precluded obtaining additional support for a follow-on multi-year CRADA, nevertheless, the investigations that were carried out in the course of the ORNL/DCI CRADA have impacted and continue to impact a number of DOEsupported research projects. The commercialization of the $\mathrm{LuPO}_{4}: \mathrm{Ce}^{3+}$ gamma-ray scintillator remains a possibility that depends on the development of a reproducible technique for the growth of large single crystals of this material. A new scintillator activated by cerium was discovered in the course of the CRADA, and future research may result in the development of this material as a practical gamma-ray detector.

\section{$\underline{\text { References }}$}

[1] R. S. Feigelson, Journal of the American Ceramic Society Discussions and Notes 47, 257 (1964).

[2] C. Brecher, H. Samelson, R. Riley, and A. Lempicki, Journal of Chemical Physics 49, 3303 (1968). 
CRADA Distribution List for C/ORNL 94-0274:

\begin{tabular}{|c|c|c|}
\hline Energy Research P.I. & $\begin{array}{l}\text { L. A. Boatner, } \\
10 \text { copies }\end{array}$ & MS-6056, Building 3150 \\
\hline OTT Business Manager & $\begin{array}{l}\text { C. A. Valentine, } \\
1 \text { copy }\end{array}$ & MS-8242, Building 701SCA \\
\hline $\begin{array}{l}\text { ORNL CRADA } \\
\text { Manager }\end{array}$ & $\begin{array}{l}\text { Joyce Shepherd, } \\
2 \text { copies }\end{array}$ & MS-6416, Building 5002 \\
\hline Participant's P.I. & $\begin{array}{l}\text { Stuart Samuelson, } \\
\text { President, } \\
5 \text { copies }\end{array}$ & $\begin{array}{l}\text { Deltronic Crystal Industries } \\
60 \text { Harding Avenue } \\
\text { Dover, NJ } 07801\end{array}$ \\
\hline \multirow[t]{2}{*}{ Line Managers } & $\begin{array}{l}\text { J. B. Roberto, } \\
1 \text { copy }\end{array}$ & MS-6033, Building 3025 \\
\hline & $\begin{array}{l}\text { B. R. Appleton, } \\
1 \text { copy }\end{array}$ & MS-6240, Building 4500-N \\
\hline Program Manager & $\begin{array}{l}\text { T. M. Rosseel, } \\
5 \text { copies }\end{array}$ & MS-6416, Building 5002 \\
\hline DOE Funding Sponsor & $\begin{array}{l}\text { W. M. Polansky, } \\
\text { Director, } \\
\text { I copy }\end{array}$ & $\begin{array}{l}\text { Headquarters Program Office } \\
\text { Advanced Energy Projects and } \\
\text { Technology Research } \\
\text { Department of Energy } \\
19901 \text { Germantown Road } \\
\text { Germantown, MD }\end{array}$ \\
\hline DOE/OSTI & $\begin{array}{l}\text { Office of Scientific \& } \\
\text { Technical Information } \\
2 \text { copies }\end{array}$ & $\begin{array}{l}\text { PO Box } 62 \\
\text { Oak Ridge, TN } 37831\end{array}$ \\
\hline Patent Counsel & $\begin{array}{l}\text { Stephen D. Hamel, } \\
\text { I copy }\end{array}$ & DOE Office of Patent Counsel \\
\hline ORNL Site Office & $\begin{array}{l}\text { Pamela L. Gorman } \\
1 \text { copy }\end{array}$ & MS-6269, Building 4500-N \\
\hline ORNL Records Office & $\begin{array}{l}\text { STIO } \\
1 \text { copy }\end{array}$ & ORNL Lab Records \\
\hline
\end{tabular}

